\title{
HBV Vaccination Status and Response to Hepatitis B Vaccine Among Iranian Dentists, Correlation With Risk Factors and Preventive Measures
}

\author{
Nafiseh Momeni ${ }^{1}$; Mohammad Sadegh Ahmad Akhoundi ${ }^{1,2}$; Seyed Moayed Alavian ${ }^{3}$; \\ Ahmad Reza Shamshiri ${ }^{4}$; Mehdy Norouzi ${ }^{5}$; Nima Mahboobi ${ }^{1}$; Nilufar Moosavi ${ }^{1}$; Seyed \\ Mohammad Jazayeri ${ }^{5,}$ \\ ${ }^{1}$ Dental Research Center, Dentistry Research Institute, Tehran University of Medical Sciences, Tehran, IR Iran \\ ${ }_{2}^{2}$ Orthodontic Department, Faculty of Dentistry, Tehran University of Medical Sciences, Tehran, IR Iran \\ ${ }^{3}$ Middle East Liver Diseases Center (MELD Center), Tehran, IR Iran \\ ${ }_{5}^{4}$ Research Center for Caries Prevention, Dentistry Research Institute, Department of Community Oral Health, Tehran University of Medical Sciences, Tehran, IR Iran \\ ${ }^{5}$ Hepatitis B Molecular Laboratory, Department of Virology, School of Public Health, Tehran University of Medical Sciences, Tehran, IR Iran \\ ${ }^{*}$ Corresponding Author: Seyed Mohammad Jazayeri, Hepatitis B Molecular Laboratory, Department of Virology, School of Public Health, Tehran University of Medical Sciences, P. O. \\ Box: 14155-6446, Tehran, IR Iran. Tel/Fax: +98-2188992660, E-mail: jazayerism@tums.ac.ir
}

Received: May 5, 2014; Accepted: December 6, 2014

\begin{abstract}
Background: Studies showed that HBV vaccination and consequent level of antibody are not completely adequate among dentists despite performance of highly exposure prone procedures.

Objectives: The objectives of the study were to evaluate the levels of responsiveness to HBV vaccine and to determine the occupational factors associated among dental staff.

Materials and Methods: In total, 1612 dental health care workers were recruited. The level of anti-HBs was tested using a commercially enzyme-linked immunosorbent assay (ELISA). Data on demographic, risk factors associated with dental practice and level of protective procedures and occupational exposure aspects were collected through self-reported questionnaires.

Results: Of 1538 vaccinated individuals, 55 (3.7\%), 126 (8.4\%) and 1309 (87.9\%) had received one, two and full three doses of vaccine, respectively. One-hundred-seventy-six (11.5\%) were nonimmune (anti-HBs $<10 \mathrm{IU} / \mathrm{mL}$ ) and $1362(88.5 \%)$ were immune (anti-HBs $>10 \mathrm{IU} /$ $\mathrm{mL}) .392 / 542$ (72.3\%) of dentists who received their third dose of vaccination less than five years before the commencement of study were completely immune compared to those who had completed all three recommended doses in a longer period (308/491, 64.3\%) $(\mathrm{P}=0.001)$. Fifty-eight (3.59\%) of participants did not receive any HBV vaccine at all; however, they had positive results for anti-HBs, indicating a past HBV infection. Statistically, the levels of anti-HBs were significantly associated with gender, age, duration of dental practice engagement and regularly use of mask, glasses and shield.

Conclusions: Since dental care workers have a high risk of exposure to hepatitis virus, they should be advised to receive hepatitis B vaccine and it should be confirmed if they have acquired immunity to HBV by testing the level of anti-HBs.
\end{abstract}

Keywords:Hepatitis B Vaccines; Dentists; Infection Control

\section{Background}

Health care workers (HCWs) are at the front line for acquiring blood-borne viruses (hepatitis B virus, HBV; hepatitis $\mathrm{C}$ virus, HCV and human immunodeficiency virus, HIV) infections. The worldwide HBV infection rate is higher in dentists than other blood borne viruses like HCV and HIV. HBsAg prevalence among dentists reported to be $0.6 \%$ in the USA (1), $2.4 \%$ in Malaysia (2) and $13 \%$ in Korea (3). Likewise, among health care workers, dentists experience the highest chance of HBV infection and HBV incidences increase with duration of clinical experience of dentistry $(4,5)$. On the other hand, past (anti-HBc positivity) or present (HBsAg positivity) HBV infection rate in dentists are usually higher than the general population, regardless of HBV endemicity in those area (6).
Among blood-borne viruses, an immunoprophylactic vaccine is only available for HBV. Despite being effective in decreasing the HBV prevalence, the Extended Program on Immunization (EPI) only targeted newborns and adults in general populations, as well as high-risk groups, including dentists. However, dental health care workers are not fully covered by HBV immunization programs. Estimated of a 100-fold reduction in the incidence of $\mathrm{HBV}$ infection in vaccinated individuals compared to non-vaccinated individuals, regardless of the vaccine response (7), indicates that dental care workers should be advised to receive hepatitis $\mathrm{B}$ vaccine and it should be confirmed if they have acquired immunity to HBV by testing the level of anti-HBs $(1,4,5,8-10)$.

Copyright (C) 2015, Kowsar Corp. This is an open-access article distributed under the terms of the Creative Commons Attribution-NonCommercial 4.0 International License (http://creativecommons.org/licenses/by-nc/4.0/) which permits copy and redistribute the material just in noncommercial usages, provided the original work is properly cited. 
Reports from different countries indicated that HBV vaccine coverage rate in dental health care workers ranged between $26 \%$ and $96.6 \%(8,9)$. In Iran, this coverage rate ranged between $74.8 \%$ and $94.9 \%$; on average $70 \%$ of dentists care workers received at least one dose of $\mathrm{HBV}$ vaccine (11). As it shown, the reported response to HBV vaccine has not been reached $100 \%$ among dentists. Response to HBV vaccine (i.e. anti-HBs levels > $10 \mathrm{IU} / \mathrm{mL}$ ) between Iranian dental workers has been studied extensively and $89.2 \%$ to $94.4 \%$ of dentists showed reasonable levels of anti-HBs following one to three doses of HBV vaccine (11-14). In the largest Iranian survey, of 598 participants, 35 (5.9\%) were nonimmune (anti-HBs $<10 \mathrm{IU} / \mathrm{L}$ ), 101 (16.9\%) were relatively immune (anti- HBs > 10-99 $\mathrm{IU} / \mathrm{L})$ and 462 (77.3\%) were completely immune (anti-HBs $>100 \mathrm{IU} / \mathrm{L})(14)$.

\section{Objectives}

The objectives of the present study were to assess the $\mathrm{HBV}$ vaccine coverage and investigate the responsiveness to HBV vaccine as well as socio-demographic data, health-related and occupational factors and other correlates of vaccine responsiveness in Iranian dentists and dental staff.

\section{Materials and Methods}

This was a cross-sectional survey of dentists attending the 51st annual international congress of Iranian dental association held on 10 to 13 may 2011. Announcements were given at the time of meeting registration and before the scientific sessions. Individuals who met our inclusion criteria and willingness to give blood samples and knowing their vaccination history were recruited. An informed consent was obtained from all enrolled participants and a questionnaire was distributed to collect data. At a special booth in the conference building, potential participants gave oral consent and completed the questionnaire.

The purpose of the study and questionnaire was explained to all participants. The items on the questionnaire included:1) demographic information, such as age, gender and marital status; 2) occupational information, comprising years of dental practice and place of practice and 3) vaccination data, which included the number of doses, time interval between doses, last dose date and checking the titer of antibody after vaccination. Among 1665 participants, history of immunization was extracted for 1612 individuals; hence 53 cases were excluded from the study. Ten millimeters of blood was obtained from each participant at the congress site. Blood samples were collected by peripheral venipuncture from all dentists. The samples were tested for antibodies against hepatitis B (anti-HBs) and anti-HBc using commercially available enzyme linked immunosorbent assays (ELISA) (M.B.S S.R.L. kit M.B.S. S.r.l. Medical Biological Service.
Italy). Anti-HBs were measured in $\mathrm{IU} / \mathrm{mL}$, and the results were classified into two groups as follows:1) titers below $10 \mathrm{IU} / \mathrm{L}$ as no immunity and 2) titers above $10 \mathrm{IU} / \mathrm{mL}$ as complete immunity.

Data was analyzed using the Statistical Package for Social Sciences (IBM Corp. Released 2011. IBM SPSS Statistics for Windows, Version 20.0, Armonk, NY: IBM Corp). All statistical comparisons were performed by simple and multiple linear regression analyses on logarithm (base 10 ) of the anti-HBs antibody values. $\mathrm{P}<0.05$ was considered as statistically significant.

\section{Results}

\subsection{General Characteristics}

1612 participants including 1300 (80.7\%) general practitioner, 155 (9.6\%) students, 120 (7.4\%) specialists and 37 (2.3\%) clinical dental assistants were studied (Table 1$)$. The subjects comprised 1058 (65.6\%) males and 554 (34.4\%) females with a mean age of 40.4 years (range $19-75$ years, results not shown). The number of years in practice ranged from 0 to 55 years (excluding students) with a median of 15 years (results not shown). The demographic characteristics of the study sample according to job classifications are shown in Table 1.

\subsection{Vaccination Status}

Of total 1538 vaccinated individuals, 176 (11.5\%) were nonimmune (anti-HBs $<10 \mathrm{IU} / \mathrm{mL}$ ) and 1362 (88.5\%) were immune (anti-HBs $>10 \mathrm{IU} / \mathrm{mL}$ ) regardless of the number of doses and time after the last dose and time intervals between doses. No significant associations were found between the levels of anti-HBs and the kind of dental job (Table 2). According to subjects' reports, 55 (3.7\%), 126 (8.4\%) and 1309 (87.9\%) had received one, two and full three doses of vaccine, respectively (See Table 1 for more details). Fifty-eight (3.59\%) of participants did not receive any HBV vaccine at all; however, they had positive results for anti-HBs, indicating a past HBV infection. Data was missing for 16 individuals.

The median of anti-HBs titer was 247 ranged between 0 and 1502. However, anti-HBs mean value was 12.96 (95\% CI: 5.72-29.39) for those who did not receive HBV vaccine. Nevertheless, the mean anti-HBs titers were 24.89 (95\% CI: 11.16-55.52), 100.32 (95\% CI: 70.52-142.72) and 107.04 (95\% CI: 96.82-118.33) for subjects who received one, two and three doses of vaccine, respectively ( $P$ values between 1 and 2; 2 and $\geq 3$ doses: 0.006 , and 0.98 , respectively, results not shown). Therefore, no significant difference was found between antibody levels and receiving second or third doses of vaccine; whereas, this association was significant between individuals who received only one versus those who received the second dose.

Among total participants, 1033 who knew their exact 
time of vaccination history, 542 (52.5\%) mentioned that they received vaccination within the past five years, while others $(491 ; 47.5 \%)$ reported having received the last dose of vaccine more than five years prior this study. $356 / 542$ (65.7\%) of dentists who had received their third dose of vaccination less than five years before the study were completely immune (anti-HBs > $100 \mathrm{IU} / \mathrm{mL}$ ); this rate was significantly higher than individuals who had completed all three recommended doses in a period more than 5 years prior to the study 279/491 (56.8\%) ( $\mathrm{P}=$ 0.003) (Table 1).

A significant relation was found between gender and anti-HBs antibody titer; females showed a higher level of anti-HBs $(\mathrm{P}=0.022)$, (Table 1$)$. Accordingly, the median of antibody titer was significantly higher in the age group $<$ 45 years compared to the age group $>45$ years $(\mathrm{P}<0.001)$. Furthermore, statistically significant associations were found between the median titer of anti-HBs following vaccination and duration of dental practice engagement $(\mathrm{P}<0.001)$ (Table 1$)$.

Eighty-one (5\%) of participants had positive results for anti-HBc, of whom 66 (81.4\%) had a history of vaccination (results not shown); 55 (83.3\%) had protective levels of anti-HBs ( $\geq 10 \mathrm{IU} / \mathrm{mL}$ ) and 11 (16.7\%) had inadequate antiHBs levels $(<10 \mathrm{IU} / \mathrm{mL})$. Although $13(16.5 \%)$ of anti-HBc positive dentists did not receive vaccine, seven had protective levels of anti-HBs and six had inadequate levels, indicating a possible past HBV infection.

Table 1. Distribution of Demographic Characteristics ${ }^{\text {a }}$

\begin{tabular}{|c|c|c|c|c|}
\hline & Student $(n=155)$ & $\begin{array}{l}\text { General Practitioner } \\
\quad(\mathbf{n}=\mathbf{1 3 0 0})\end{array}$ & Specialist $(\mathbf{n}=120)$ & Resident $(\mathbf{n}=37)$ \\
\hline Age, $y$ & $23.93 \pm 3.61$ & $42.47 \pm 9.94$ & $43.4 \pm 10.53$ & $28.78 \pm 3.25$ \\
\hline \multicolumn{5}{|l|}{ Gender } \\
\hline Male & $60(38.71)$ & $905(69.62)$ & $82(68.33)$ & $11(29.73)$ \\
\hline Female & $95(61.29)$ & $395(30.38)$ & $38(31.67)$ & $26(70.27)$ \\
\hline \multicolumn{5}{|c|}{ Hepatitis vaccination } \\
\hline No & $13(8.39)$ & $38(2.92)$ & $8(6.67)$ & $0(0)$ \\
\hline Yes & $142(91.61)$ & $1262(97.08)$ & $112(93.33)$ & $37(100)$ \\
\hline \multicolumn{5}{|l|}{$\begin{array}{l}\text { Years from the last } \\
\text { vaccination, } y\end{array}$} \\
\hline No vaccination & $13(8.39)$ & $38(2.92)$ & $8(6.67)$ & $0(0)$ \\
\hline$\leq 5$ & $98(63.22)$ & $408(31.37)$ & $28(23.33)$ & $14(37.84)$ \\
\hline$>5$ & $11(7.10)$ & $429(33.00)$ & $41(34.17)$ & $17(45.95)$ \\
\hline Unknown & $33(21.29)$ & $425(32.69)$ & $43(35.83)$ & $6(16.21)$ \\
\hline \multicolumn{5}{|l|}{ Number of doses } \\
\hline None & $13(8.39)$ & $38(2.92)$ & $8(6.67)$ & $0(0.00)$ \\
\hline One dose & $15(9.68)$ & $37(2.85)$ & $3(2.50)$ & $0(0.00)$ \\
\hline Two doses & $11(7.10)$ & $101(7.77)$ & 14 (11.67) & $2(5.41)$ \\
\hline$\geq 3$ Doses & $108(69.68)$ & $1093(84.08)$ & $91(75.83)$ & $35(94.59)$ \\
\hline Unknown & $8(5.15)$ & $31(2.38)$ & $4(3.33)$ & $0(0.00)$ \\
\hline Years of working & 0 & $15.55 \pm 9.35$ & $16.14 \pm 9.02$ & $7.54 \pm 3.23$ \\
\hline \multicolumn{5}{|l|}{ Marital status } \\
\hline Single & $134(86.45)$ & $230(17.69)$ & $19(15.83)$ & $17(45.95)$ \\
\hline Married & $21(13.55)$ & $1070(82.31)$ & $101(84.17)$ & $20(54.05)$ \\
\hline
\end{tabular}

a Data are presented as mean \pm SD or No. (\%). 
Table 2. Association Between Anti-HBs Antibody Status and Demographic, Type of Dental Activity, Vaccination Details, Risk Factors and Using Protective Measures ${ }^{a}$

\begin{tabular}{|c|c|c|c|c|}
\hline & Anti-HBs, IU/mL ${ }^{b}$ & Regression Coefficient & 95\% CI & P Value \\
\hline Age & - & -0.011 & $-0.015--0.007$ & $<0.001$ \\
\hline \multicolumn{5}{|l|}{ Job description } \\
\hline Student & $234.26 \pm 17.65$ & Ref. & & \\
\hline General practitioner & $214.25 \pm 5.48$ & 0.0004 & $-0.147-0.148$ & 0.996 \\
\hline Specialist & $202.77 \pm 11.51$ & 0.069 & $-0.096-0.235$ & 0.413 \\
\hline Dental assistant & $190.02 \pm 19.41$ & 0.027 & $-0.262-0.316$ & 0.853 \\
\hline \multicolumn{5}{|c|}{ Time from last vaccination, $y$} \\
\hline$\leq 5$ & $254.58 \pm 10.07$ & Ref. & & \\
\hline$>5$ & $191.77 \pm 7.97$ & -0.201 & $-0.309--0.094$ & $<0.001$ \\
\hline No vaccination & $147.34 \pm 31.31$ & -0.981 & $-1.216--0.746$ & $<0.001$ \\
\hline \multicolumn{5}{|l|}{ Number of vaccine doses } \\
\hline None & $147.34 \pm 31.31$ & Ref. & & \\
\hline One dose & $145.02 \pm 22.38$ & 0.283 & $-0.033-0.599$ & 0.079 \\
\hline 2 doses & $238.22 \pm 21.95$ & 0.889 & $0.623-1.154$ & $<0.001$ \\
\hline$\geq 3$ doses & $220.03 \pm 5.16$ & 0.917 & $0.693-1.14$ & $<0.001$ \\
\hline Unknown doses & $180.57 \pm 27.24$ & 0.649 & $0.315-0.983$ & $<0.001$ \\
\hline \multicolumn{5}{|l|}{ Gender } \\
\hline Male & $209.55 \pm 5.81$ & Ref. & & \\
\hline Female & $223.81 \pm 8.43$ & 0.106 & $1.874-0.197$ & 0.022 \\
\hline Working experience, $y$ & - & -0.011 & $-0.016--0.007$ & $<0.001$ \\
\hline \multicolumn{5}{|l|}{ Marital status } \\
\hline Single & $227.86 \pm 10.12$ & Ref. & & \\
\hline Married & $210.31 \pm 5.52$ & -0.075 & $-0.176-0.026$ & 0.145 \\
\hline \multicolumn{5}{|l|}{ History of needle stick } \\
\hline negative & $215.84 \pm 8.77$ & Ref. & & \\
\hline positive & $213.24 \pm 5.82$ & 0.034 & $-0.059-0.127$ & 0.468 \\
\hline Number of needle stick & - & 0.007 & $-0.013-0.027$ & 0.495 \\
\hline \multicolumn{5}{|l|}{ Liver disease } \\
\hline negative & $213.62 \pm 4.90$ & Ref. & & \\
\hline positive & $225.07 \pm 21.15$ & -0.112 & $-0.28-0.055$ & 0.188 \\
\hline \multicolumn{5}{|l|}{ Sharp Trauma } \\
\hline negative & $216.28 \pm 5.00$ & Ref. & & \\
\hline positive & $180.19 \pm 18.16$ & -0.106 & $-0.324-0.112$ & 0.34 \\
\hline \multicolumn{5}{|l|}{ Sex contact } \\
\hline negative & $214.52 \pm 4.91$ & Ref. & & \\
\hline positive & $218.18 \pm 30.35$ & -0.115 & $-0.409-0.179$ & 0.442 \\
\hline \multicolumn{5}{|l|}{ History of transfusion } \\
\hline negative & $216.94 \pm 5.05$ & Ref. & & \\
\hline positive & $178.00 \pm 15.73$ & -0.234 & $-0.423--0.044$ & 0.016 \\
\hline \multicolumn{5}{|c|}{ History of hepatitis in parents } \\
\hline negative & $214.42 \pm 4.89$ & Ref. & & \\
\hline positive & $226.29 \pm 39.11$ & 0.07 & $-0.258-0.397$ & 0.676 \\
\hline
\end{tabular}

Gloves 
Momeni $N$ et al.

\begin{tabular}{|c|c|c|c|c|}
\hline Regular use of gloves & $215.52 \pm 4.94$ & 0.15 & $-0.147-0.447$ & 0.322 \\
\hline Irregular or never used & $197.15 \pm 25.02$ & Ref. & & \\
\hline \multicolumn{5}{|l|}{ Mask } \\
\hline Regular use of mask & $216.11 \pm 5.00$ & 0.192 & $-0.032-0.416$ & 0.093 \\
\hline Irregular or never used & $163.35 \pm 17.50$ & Ref. & & \\
\hline \multicolumn{5}{|l|}{ Glasses } \\
\hline Regular use of glasses & $212.91 \pm 5.36$ & 0.075 & $-0.029-0.179$ & 0.158 \\
\hline Irregular or never used & $214.35 \pm 10.74$ & Ref. & & \\
\hline \multicolumn{5}{|l|}{ Shield } \\
\hline Regular use of shield & $226.78 \pm 8.27$ & 0.072 & $-0.02-0.164$ & 0.127 \\
\hline Irregular or never used & $207.85 \pm 6.27$ & Ref. & & \\
\hline \multicolumn{5}{|l|}{ Smoking } \\
\hline Smoker & $201.04 \pm 10.31$ & -0.032 & $-0.164-0.101$ & 0.64 \\
\hline Non-smoker & $221.32 \pm 6.26$ & Ref. & & \\
\hline
\end{tabular}

$\mathrm{b}$ Data are presented as mean \pm SE.

\subsection{Risk Factors and Anti-HBs Status}

To determine possible risk factors and anti-HBs levels, no significant associations were found between levels of antibody titers and number of needle stick as well as other risk factors such as trauma, suspicious sexual contact and a history of liver disease (Table 2). However, a significant negative association was found between the history of transfusion and low levels of anti-HBs $(\mathrm{P}=0.016)$ (Table 2).

of 1385 cases with known cigarette smoking history, there were 211 (15.2\%) dentists who were smokers. The median of years for smoking was 14 and the median of packyears of smoking was 3.75 (results not shown). However, there was no significant association between antibody titer and history, duration and pack-years of smoking $(\mathrm{P}=$ $0.1,0.38$ and 0.37 , respectively).

\subsection{Anti-HBs Status and Using Protecting Mea- sures}

Among participants, anti-HBs levels were not different according to consistent use of gloves $(\mathrm{P}=0.322$; Table 2). On the other hand, anti-HBs levels for those who regularly used mask, glasses and shield were higher than those who used them irregularly or not at all, although they were not significant statistically $(\mathrm{P}=0.093,0.158$ and 0.127 , respectively; Table 2).

\section{Discussion}

This study was performed to determine the anti-HBs antibody titers of Iranian dental care workers and to investigate the possible correlation between demographic features as well as details of vaccination schedule with anti-HBs antibody titer in this population. Moreover, risk factors related to immune status of subjects together with protective measurement were considered in this investigation. Although the study sample was not selected randomly, our sample size was the largest among Iranian researches. In the present investigation, $1538 \mathrm{HBV}$ vaccine recipients were anti-HBs-positive, of whom 1362 (88.5\%) subjects developed adequate levels of antibody to HBV infection and 176 (11.5\%) were non-immune. A similar study on dentists in Iran showed that $69 \%-77 \%$ of participants were completely immune, while $17 \%$ were relatively immune and $6-13 \%$ were non-immune $(12,14)$. The number of those who had received their three recommended doses of vaccine was 1312 (87.9\%). Furthermore, statistically significant correlations were found between the median titer of anti-HBs following vaccination and time after the last vaccine injection $(\mathrm{P}<0.001)$.

Regarding very low to moderate levels of anti-HBs (< $10-100 \mathrm{IU} / \mathrm{mL})$ in $481(31.3 \%)$ participants, they are at increased risk for HBV infection (15-17). There are two possibilities:(i) decline in the antibody titer with the passage of time despite initial adequate levels of anti-HBs. In the present study, the difference between the times lasting from the third dose of vaccine was statistically significant $(>5$ years $v s .<5$ years). Similar studies showed that in individuals who respond adequately to vaccination, anti-HBs antibody levels decrease over time and may fall below protective levels. Basically, administering a booster dose of HBs Ag vaccine results in a vigorous anamnestic response, demonstrating that immune memory against HBV infection lasts longer than antiHBs antibodies $(18,19)$. On the other hand, (ii) the other possibility is nonresponsiveness to the vaccine. Several factors were reported to influence the response to HBV vaccine in nonresponders such as genetic background, older age, obesity $(20,21)$ and smoking $(9,22)$. For those who do not respond to the primary vaccination series, an additional regimen of ordinary vaccines (either administration of a higher dose or a second course of three doses of HBV recombinant vaccine) usually gives rise to about 
$15 \%$ to $25 \%$ and $30 \%$ to $50 \%$ of responsiveness to one and three additional doses, respectively $(23,24)$. Likewise, still more than $50 \%$ of non-responders are not able to acquire protective levels of anti-HBs despite administration of at least two additional booster recombinant vaccines (25, 26). Alternate schedule includes intradermal vaccine administration (27) or third generation vaccines (that contained Pre-S1/Pre-S2 proteins through recombinant technology in mammalian cell lines) with higher immunogenicity and more seroconversion rate compared to the second generation vaccines $(28,29)$. Otherwise, for those persistent nonresponders, it is recommended to avoid EPP (exposure-prone procedures) and they should be noticed that they may be susceptible to HBV and that they should receive hepatitis B immune globulin (HBIG) following HBV exposure (30). We did not check anti-HBc status of participants, hence anti-HBs level in the study does not necessarily differentiate rising of antibody following vaccination or past infection with HBV.

In the present study, the rate of incomplete vaccinations was $13 \%$, hence more efforts should be made to persuade all dentists to receive the three doses of vaccine. Unfortunately, as worldwide, no mandatory HBV vaccination program exists for dentists in Iran, which may cause a low rate of compliance in voluntary vaccination program(s) now available for HCWs at health offices. It is of some concern that dentists are willing to accept significant degree of personal risk, despite recorded danger from hepatitis $\mathrm{B}$, either by failing to ensure immunization against hepatitis B or by failing to check the presence of hepatitis B antibodies following immunization.

In conclusion, HBV vaccine coverage and infection control measures were satisfactory among Iranian dental personnel in this study. Since dental care workers have a high risk of exposure to hepatitis virus, a compulsory vaccination for hepatitis B virus is desirable for all dental care workers.

\section{Authors' Contributions}

Study concept and design: Ahmad Akhoundi, Momeni, Jazayeri and Alavian. Sampling and executive procedure: Momeni, Ahmad Akhoundi, Norouzi, Mahboobi, Moosavi and Jazayeri. Drafting of the manuscript: Momeni, Ahmad Akhoundi and Jazayeri. Statistical analysis: Shamshiri.

\section{Funding/Support}

This study was supported by Tehran University of Medical Sciences (Grant No: 132/2212).

\section{References}

1. Shah SM, Merchant AT, Dosman JA. Percutaneous injuries among dental professionals in Washington State. BMC Public Health. 2006;6:269.

2. Vadivale M, Tan TC, Ong CN. Sero-prevalence of hepatitis B infection among dental professionals. Singapore Med J. 1992; 33(4):367-9.
3. Song KB, Choi KS, Lang WP, Jacobson JJ. Hepatitis B prevalence and infection control among dental health care workers in a community in South Korea. J Public Health Dent. 1999;59(1):39-43.

4. Reingold AL, Kane MA, Hightower AW. Failure of gloves and other protective devices to prevent transmission of hepatitis B virus to oral surgeons. JAMA. 1988;259(17):2558-60.

5. Thomas DL, Gruninger SE, Siew C, Joy ED, Quinn TC. Occupational risk of hepatitis $\mathrm{C}$ infections among general dentists and oral surgeons in North America. Am J Med.1996;100(1):41-5.

6. Mahboobi N, Agha-Hosseini F, Safari S, Lavanchy D, Alavian SM. Hepatitis B virus infection in dentistry: a forgotten topic. J Viral Hepat. 2010;17(5):307-16.

7. Hofmann F, Kralj N. Criteria for successful hepatitis B vaccination in adults: results of a case study. Infection. 2009;37(3):266-9.

8. Ammon A, Reichart PA, Pauli G, Petersen LR. Hepatitis B and C among Berlin dental personnel: incidence, risk factors, and ef fectiveness of barrier prevention measures. Epidemiol Infect. 2000;125(2):407-13.

9. Batista SM, Andreasi MS, Borges AM, Lindenberg AS, Silva AL, Fernandes TD, et al. Seropositivity for hepatitis B virus, vaccination coverage, and vaccine response in dentists from Campo Grande, Mato Grosso do Sul, Brazil. Mem Inst Oswaldo Cruz. 2006;101(3):263-7.

10. Cleveland JL, Siew C, Lockwood SA, Gruninger SE, Gooch BF, Shapiro CN. Hepatitis B vaccination and infection among U.S. dentists, 1983-1992. J Am Dent Assoc. 1996;127(9):1385-90.

11. Alavian SM, Akbari H, Ahmadzad-Asl M, Kazem M, Davoudi A Tavangar H. Concerns regarding dentists' compliance in hepatitis B vaccination and infection control. Am J Infect Control. 2005;33(7):428-9.

12. Alavian SM, Mahboobi N. Anti-HBs antibody status and some of its associated factors in dental health care workers in Tehran University of Medical Sciences: Anti-HBs Ab and associated factors in dental society. Hepat Mon. 2011;11(2):99-102.

13. Alavian SM, Mahboobi N, Savadrudbari MM, Azar PS, Daneshvar S Iranian dental students' knowledge of hepatitis B virus infection and its control practices. J Dent Educ. 2011;75(12):1627-34.

14. Alavian SM, Izadi M, Zare AA, Lankarani MM, Assari S, Vardi MM Survey of the level of anti-HBs antibody titer in vaccinated Iranian general dentists. Spec Care Dentist. 2008;28(6):265-70.

15. McMahon BJ, Bruden DL, Petersen KM, Bulkow LR, Parkinson AJ, Nainan O, et al. Antibody levels and protection after hepatitis B vaccination: results of a 15-year follow-up. Ann Intern Med. 2005;142(5):333-41.

16. Desombere I, Hauser P, Rossau R, Paradijs J, Leroux-Roels G. Nonresponders to hepatitis $\mathrm{B}$ vaccine can present envelope particles to T lymphocytes. J Immunol. 1995;154(2):520-9.

17. Bialek SR, Bower WA, Novak R, Helgenberger L, Auerbach SB, Williams IT, et al. Persistence of protection against hepatitis B virus infection among adolescents vaccinated with recombinant hepatitis B vaccine beginning at birth: a 15-year follow-up study. Pediatr Infect Dis J. 2008;27(10):881-5.

18. Valats JC, Tuaillon E, Funakoshi N, Hoa D, Brabet MC, Bollore K, et al. Investigation of memory B cell responses to hepatitis B surface antigen in health care workers considered as non-responders to vaccination. Vaccine. 2010;28(39):6411-6.

19. Williams JL, Christensen CJ, McMahon BJ, Bulkow LR, Cagle HH Mayers JS, et al. Evaluation of the response to a booster dose of hepatitis $\mathrm{B}$ vaccine in previously immunized healthcare workers. Vaccine. 2001;19(28-29):4081-5.

20. Milich DR, Leroux-Roels GG. Immunogenetics of the response to HBsAg vaccination. Autoimmun Rev. 2003;2(5):248-57.

21. Hohler T, Stradmann-Bellinghausen B, Starke R, Sanger R, Victor A, Rittner C, et al. C4A deficiency and nonresponse to hepatitis B vaccination. J Hepatol. 2002;37(3):387-92.

22. Chen W, Gluud C. Vaccines for preventing hepatitis B in healthcare workers. Cochrane Database Syst Rev. 2005(4):CD000100.

23. Alimonos K, Nafziger AN, Murray J, Bertino JS, Jr.. Prediction of response to hepatitis B vaccine in health care workers: whose titers of antibody to hepatitis B surface antigen should be determined after a three-dose series, and what are the implications in terms of cost-effectiveness? Clin Infect Dis. 1998;26(3):566-71. 


\section{Momeni $N$ et al.}

24. Sjogren MH. Prevention of hepatitis B in nonresponders to initial hepatitis B virus vaccination. Am J Med. 2005;118 Suppl 10A:34S-9S.

25. Zuckerman JN, Sabin C, Craig FM, Williams A, Zuckerman AJ. Immune response to a new hepatitis $B$ vaccine in healthcare workers who had not responded to standard vaccine: randomised double blind dose-response study. BMJ.1997;314(7077):329-33.

26. Averhoff F, Mahoney F, Coleman P, Schatz G, Hurwitz E, Margolis H. Immunogenicity of hepatitis B Vaccines. Implications for persons at occupational risk of hepatitis B virus infection. Am J Prev Med.1998;15(1):1-8.

27. Propst T, Propst A, Lhotta K, Vogel W, Konig P. Reinforced intra- dermal hepatitis B vaccination in hemodialysis patients is superior in antibody response to intramuscular or subcutaneous vaccination. Am J Kidney Dis. 1998;32(6):1041-5.

28. Raz R, Koren R, Bass D. Safety and immunogenicity of a new mammalian cell-derived recombinant hepatitis B vaccine containing Pre-S1 and Pre-S2 antigens in adults. Isr Med Assoc J. 2001;3(5):328-32.

29. Yap I, Guan R, Chan SH. Recombinant DNA hepatitis B vaccine containing Pre-S components of the HBV coat protein--a preliminary study on immunogenicity. Vaccine. 1992;10(7):439-42.

30. John M. Hepatitis B immunization and postimmunization serology. J Can Dent Assoc. 2000;66(10):551-2. 